\title{
Analysis of the water quality condition of the Zijiang River in summer and the applicability of evaluation methods
}

\author{
Tao Zhang ${ }^{1, *}$, Peng Xiang ${ }^{2}$, Shijiang Zhu ${ }^{2, *}$, Yang $\mathrm{Liu}^{3}$,Wen $\mathrm{Xu}^{2}$,Xiaoling $\mathrm{Li}^{2}$,Aihua $\mathrm{Sun}^{2}$,Wan Meng ${ }^{2}$, Shubiao Gui ${ }^{2}$,Jin \\ $\mathrm{Zhu}^{2}$ \\ ${ }^{1}$ Yichang Dongfengqu Irrigation Area Administration,China \\ ${ }^{2}$ College of Hydraulic and Environmental Engineering, China Three Gorges University \\ ${ }^{3}$ China Institute of Water Resources and Hydropower Research \\ * Author:T.Zhang, mainly engaged in the management and research of water conservancy and water ecology.
}

\begin{abstract}
The single-factor evaluation method, improved Nemerow index method, fuzzy mathematical synthesis evaluation method and comprehensive nutrient status index method were used to evaluate the water quality of the Zijiang River in summer, and to analyze the applicability of the evaluation methods. The results show that: (1) The Zijiang River is heavily polluted with nitrogen and TN is the main pollutant in the summer. The overall nutrient status index is 34.33 , which is not eutrophic. (2) The single-factor evaluation method is simple and suitable for rapid identification of excessive pollutants, but cannot reflect the water quality. the Nemerow index method takes into account the weight of each evaluation factor in the river water quality, and is suitable for making a comprehensive evaluation of the river water quality, but has a certain degree of subjectivity when classifying the water quality. The fuzzy comprehensive evaluation method is suitable for reflecting the influence of different evaluation factors on water quality by calculating the weight and membership degree of each evaluation factor, but the calculation is complicated.The Integrated Nutrient Status Index method is suitable for determining whether eutrophication is occurring in a water body and cannot determine the water quality category.
\end{abstract}

\section{Introduction}

Comprehensive research and application of water quality evaluation methods at home and abroad, there is currently no unified evaluation method[1].It has been found that there are seasonal characteristics of water quality in rivers and lakes[2,3,4], this paper uses the widely used single-factor evaluation method, improved Nemerow index method, fuzzy mathematical evaluation method, integrated nutrient status index method, four methods to evaluate the water quality of the Zijiang River in summer, and the applicability of the four evaluation methods analysis.

\section{Materials and methods}

\subsection{Overview of Zijiang}

Zijiang River is the third largest tributary of the Dongting Lake in the central part of Hunan province.With a total length of $653 \mathrm{~km}$ and a watershed area of $28142 \mathrm{~km}^{2}$, the annual precipitation is $1200 \mathrm{~mm}-1800 \mathrm{~mm}$, and it rains a lot from April to August, and the runoff of the Zijiang River increases significantly in July [5].

\subsection{Water samples taken}

Water withdrawals along the main stem of the Zijiang River from June 27 to July 1, 2019. A total of 36 intake sections, each taking surface, middle, and bottom water at the left, middle, and right banks, respectively.From July 2 to 4, 2019, five indicators including total nitrogen, total phosphorus, ammonia nitrogen, permanganate index and chlorophyll a were measured in the laboratory of Three Gorges University. The sample point layout is shown in Fig 1.

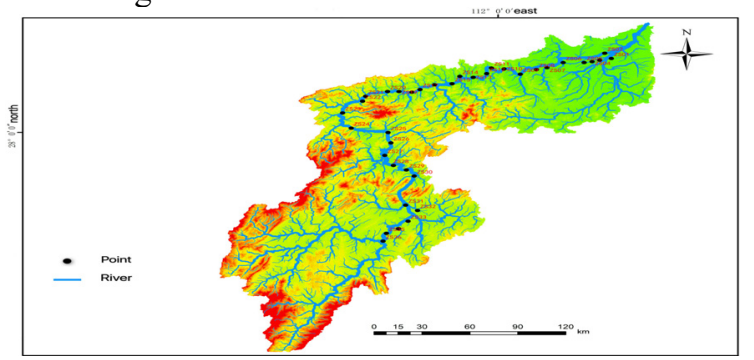

Fig 1.Distribution of sampling points

\footnotetext{
${ }^{*}$ Corresponding author:S.J.Zhu, PhD, associate professor, Email:46212465@qq.com.
} 


\subsection{Water quality assessment methods}

\subsubsection{Single factor evaluation method}

Single-factor evaluation is a method to determine the water quality level by comparing the extreme or average value of the evaluation factor with the magnitude of the standard value. The formula is $[6,7]$ :

$$
P_{\mathrm{i}}=\frac{C_{\mathrm{i}}}{C_{0}}
$$

$\mathrm{Pi}$ is the relative pollution value of an indicator, $\mathrm{Ci}$ is the maximum measured concentration value of an indicator,and $\mathrm{C}_{0}$ is the maximum allowable standard value of an indicator.

\subsubsection{Fuzzy mathematical synthesis evaluation method}

The specific steps are as follows [8,9]:

(1)Establish the evaluation object factor set $\mathrm{U}=\{\mathrm{U} 1, \mathrm{U} 2, \mathrm{U} 3, \mathrm{U} 4, \mathrm{U} 5\}$, where $\mathrm{U}$ is the measured mass concentration value of the $n$ pollution indicators involved in the evaluation.

(2)Establish the evaluation set $\mathrm{v}=\{\mathrm{I}, \mathrm{II}, \mathrm{III}, \mathrm{IV}, \mathrm{V}\}$.

(3)Determine the weight coefficients and the normalization process. Each evaluation factor $\mathrm{Ui}$ is given a weight ai according to the principle of "the more the measured concentration exceeds the standard limit, the greater the weight", and the weights of the $n$ evaluation factors constitute the weight set $\mathrm{A}=\{\mathrm{a} 1, \mathrm{a} 2, \mathrm{a} 3, \mathrm{a} 4, \mathrm{a} 5\}$. The formula for determining the weights according to the superscalar multiplier method is:

$$
\begin{gathered}
S_{\mathrm{i}}{ }^{\prime}=\frac{1}{\mathrm{~m}} \sum_{\mathrm{j}=1}^{\mathrm{n}} S_{\mathrm{ij}} \\
I_{\mathrm{i}}=\frac{X_{\mathrm{i}}}{\overline{S_{\mathrm{i}}}} \\
W_{\mathrm{i}}=\frac{I_{\mathrm{i}}}{\sum_{\mathrm{j}=1}^{\mathrm{n}} I_{\mathrm{i}}}
\end{gathered}
$$

$X_{i}$ is the measured value of factor $i, S_{i j}$ is the $j_{t h}$ criterion of factor $i, m$ is the number of levels of evaluation criteria, $\mathrm{Si}^{\prime}$ is the average value of the various levels of criteria of factor $i, W_{i}$ is the weight of the $i$-th evaluation factor, and the normalization process yields the weight set, $\mathrm{W}=\{\mathrm{W} 1, \mathrm{~W} 2, \ldots, \mathrm{Wn}\}$.

(4)Establishment of affiliation functions:

$$
\mathrm{r}_{\mathrm{ij}}= \begin{cases}1, & X_{\mathrm{i}}<S_{\mathrm{j}} \\ \frac{S_{\mathrm{j}+1}-X_{\mathrm{i}}}{S_{\mathrm{j}+1}-S_{\mathrm{j}}}, & S_{\mathrm{j}}<X_{\mathrm{i}}<S_{\mathrm{j}+1} \\ 0 & , \mathrm{X}_{\mathrm{i}} \geq \mathrm{S}_{\mathrm{j}+1}\end{cases}
$$

rij indicates the affiliation of evaluation factor $i$ to level $\mathrm{j}(\mathrm{i}=1,2, \ldots, \mathrm{n} ; \mathrm{j}=1,2, \ldots, \mathrm{m}), \mathrm{Xi}$ is the measured value of evaluation factor $\mathrm{i}$, and $\mathrm{Sj}$ indicates the water quality criterion for level $\mathrm{j}$ of evaluation factor $\mathrm{i}$. The water quality criterion for level $\mathrm{j}$ of evaluation factor $\mathrm{i}$ is indicated.

(5)The fuzzy relationship between water quality evaluation factors and evaluation criteria is established, and the $m \times n$ fuzzy evaluation matrix $\mathrm{R}$ :

$$
R=\left[\begin{array}{llll}
\mathbf{I}_{11} & \mathbf{I}_{12} & \cdots & \mathbf{r}_{\mathbf{I m}} \\
\vdots & & & \\
\mathbf{r}_{\mathrm{nl}} & \mathbf{r}_{\mathbf{2} 2} & \cdots & \mathbf{r}_{\mathbf{m}}
\end{array}\right]
$$

(6)Matrix Compounding, Development of Integrated Evaluation Models:

$$
B=W * R
$$

Based on the principle of affiliation, the quality of the water body is rated $\mathrm{j}$.

\subsubsection{Improvement of the Nemerow index method}

The formula is as follows [10]:

$$
F_{\mathrm{i}}=\frac{C_{\mathrm{i}}}{S_{\mathrm{ij}}}
$$

$$
P=\sqrt{\frac{F_{\text {Max }}{ }^{2}+F^{\prime^{2}}}{2}}
$$

$\mathrm{C}_{\mathrm{i}}$ is the measured concentration of the category $\mathrm{i}$ evaluation factor, $S_{i j}$ is the category $j$ standard concentration of the category $i$ evaluation factor, and $F_{\text {Max }}$ is the maximum value of $F_{i}$, which is the value corresponding to the pollution factor with the greatest weight.

$$
\begin{aligned}
& \mathrm{r}_{\mathrm{i}}=\frac{\mathrm{s}_{\mathrm{Max}}}{\mathrm{s}_{\mathrm{i}}} \\
& \mathrm{w}_{\mathrm{i}}=\frac{\mathrm{r}_{\mathrm{i}}}{\sum_{\mathrm{i}=1}^{\mathrm{m}} \mathrm{r}_{\mathrm{i}}}
\end{aligned}
$$

$r_{i}$ is the correlation ratio for the $i$-th pollutant, $s_{i}$ is the standard value for each pollutant, $\mathrm{s}_{\mathrm{Max}}$ is the maximum standard value for the i-th pollutant, and $\mathrm{m}$ is the number of pollutants evaluated.

\subsubsection{Comprehensive nutrient status index method}

Four detection indicators of chlorophyll a (Chl-a), TP, TN, and $\mathrm{COD}_{\mathrm{Mn}}$ were chosen for the study, which were calculated as follows [11,12]:

$$
\begin{aligned}
& \text { TLI }(\text { Chl-a })=10 \times(2.5+1.086 \ln C h l-a) \\
& \text { TLI }(T P)=10 \times(9.436+1.624 \ln T P) \\
& \text { TLI }(T N)=10 \times(5.453+1.694 \ln T N) \\
& \text { TLI }\left(C O D D_{M n}\right)=10 \times\left(0.109+2.661 \operatorname{lnCOD}_{M n}\right.
\end{aligned}
$$

$\mathrm{TLI}(\mathrm{Chl}-\mathrm{a})$ is the chlorophyll a nutrient index, TLI(TP) is the total phosphorus nutrient index, TLI(TN) is the total nitrogen nutrient index, and TLICODMn is 
the potassium permanganate nutrient index.

$$
\begin{gathered}
\operatorname{TLI}(\Sigma)=\sum_{\mathrm{j}=1}^{\mathrm{m}} \mathrm{w}_{\mathrm{j}} \times \operatorname{TLI}(\mathrm{j}) \\
\mathrm{Wj}=\frac{\mathrm{r}_{\mathrm{ij}}{ }^{2}}{\sum_{\mathrm{j}=1}^{\mathrm{m}} \mathrm{r}_{\mathrm{ij}}{ }^{2}}
\end{gathered}
$$

$\operatorname{TLI}\left(\sum\right)$ is the composite nutritional status index, $\mathrm{Wj}$ is the relevant weight of the nutritional status index for the jth parameter, TLI $(j)$ is the nutritional status index for the $\mathrm{jth}$ parameter, and $\mathrm{m}$ is the number of parameters evaluated.

Table 1. The value of each parameter

\begin{tabular}{ccc}
\hline parameter & $\mathrm{r}_{\mathrm{ij}}$ & $\mathrm{r}_{\mathrm{ij}}^{2}$ \\
\hline Chl-a & 1 & 1 \\
$\mathrm{TP}$ & 0.84 & 0.7056 \\
$\mathrm{TN}$ & 0.82 & 0.6724 \\
$\mathrm{COD}_{\mathrm{Mn}}$ & 0.83 & 0.6889 \\
\hline
\end{tabular}

Table 2. Nutritional Status Index Rating

\begin{tabular}{ccc}
\hline No & classification & $\operatorname{TLI}\left(\sum\right)$ \\
\hline 1 & Poor nutrition & $\operatorname{TLI}\left(\sum\right)<30$ \\
2 & Medium nutrition & $30 \leqq \mathrm{TLI}\left(\sum\right) \leqq 50$ \\
3 & Eutrophication & $\operatorname{TLI}\left(\sum\right)>50$ \\
4 & Mild eutrophication & $<50 \mathrm{TLI}\left(\sum\right) \leqq 60$ \\
5 & Moderate eutrophication & $<60 \mathrm{TLI}\left(\sum\right) \leqq 70$ \\
6 & Severe eutrophication & $\mathrm{TLI}\left(\sum\right)>70$ \\
\hline
\end{tabular}

\section{Results and analysis}

\subsection{Single factor evaluation method}

The relative pollution value $\mathrm{P}_{\mathrm{i}}$ was calculated from the single-factor evaluation formula, and the Pi values for TP, NH3-N, and $\mathrm{COD}_{\mathrm{Mn}}$ were all less than 1. TN had 14 sections with $\mathrm{P}_{\mathrm{i}}$ values greater than 1 , namely ZS02, ZS03, ZS06, ZS07, ZS08, ZS10, ZS15, ZS16, ZS21, $\mathrm{ZS} 24, \mathrm{ZS} 25, \mathrm{ZS} 29, \mathrm{ZS} 33$, and ZS35. The proportion is $39 \%$. Fig 2 shows the relative pollution value of $\mathrm{TN}$, and the measured TN concentrations in the 14 sections with $\mathrm{P}_{\mathrm{i}}$ values greater than 1 are all greater than $2.0 \mathrm{mg} . \mathrm{L}^{-1}$ in the Surface Water Quality Standard V, and TN can be judged as a pollutant exceeding the standard.

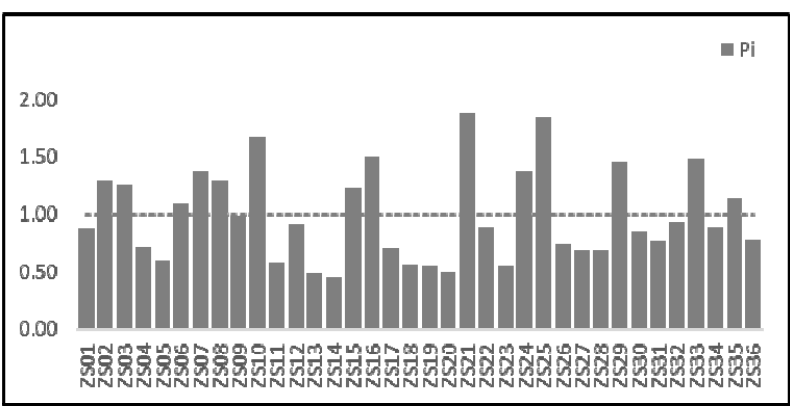

Fig 2.Relative pollution value

\subsection{Fuzzy mathematical synthesis evaluation method}

The fuzzy mathematical comprehensive evaluation method was applied to evaluate 36 cross sections, most of which are class III and have good water quality, with 10 cross sections in ZS10, ZS16, ZS17, ZS19, ZS21, ZS24, ZS25, ZS29, ZS32, ZS36 having poor water quality.

Through the analysis of weights $\mathrm{W}_{\mathrm{i}}$, the 10 sections of poor water quality $\mathrm{TN}$ accounted for the largest weight $\mathrm{W}_{\mathrm{i}}$, such as Fig 3 , in order of $0.707,0.763,0.605,0.632$, $0.828,0.764,0.817,0.764,0.588,0.692$, indicating that $\mathrm{TN}$ is the main pollution factor, ZS10, ZS17, ZS24, ZS32 section NH3-N weights $\mathrm{W}_{\mathrm{i}}$ were $0.190,0.230,0.104$, 0.249 , second only to $\mathrm{TN}$ weights, indicating that $\mathrm{NH}_{3}-\mathrm{N}$ is a minor pollution factor, ZS16, ZS19, ZS21, ZS25, ZS29, ZS36 section $\mathrm{COD}_{\mathrm{Mn}}$ weights Wi were 0.101, $0.206,0.072,0.1110 .105$ and 0.172 , second only to the TN weight, indicating a high degree of contamination by organic pollutants and reducing substances; among the 10 sections, the TP weight $\mathrm{W}_{\mathrm{i}}$ was smaller than the other three indicators, indicating that TP has the lowest degree of influence on water pollution.

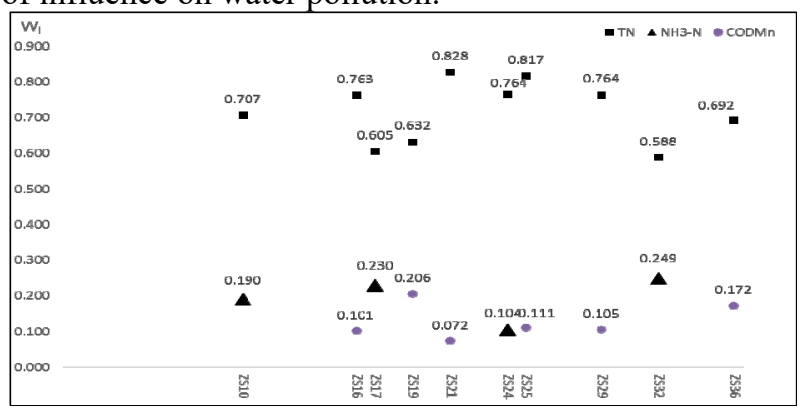

Fig 3. Weight $\mathrm{W}_{\mathrm{i}}$

\subsection{Improvement of the Nemerow index method}

The improved Nemerow index method was applied to evaluate the water quality of 36 sections, and the improved Nemerow index $\mathrm{P}$ is shown in Fig 4. 


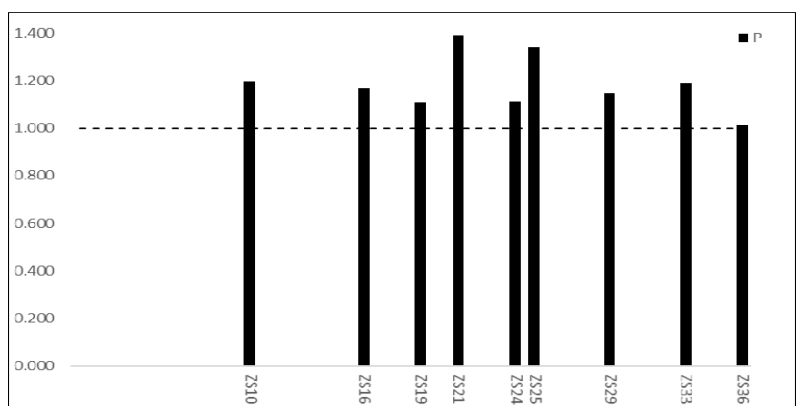

Fig 4.Nemerow Index

\subsection{Comprehensive nutrient status index method}

Using the integrated nutrient status index method, the nutrient status index $\mathrm{TLI}<50$ was calculated for 36 sections, with a maximum TLI value of 43.12 and a mean value of 34.33 , which is a medium nutrient level and the water body is not eutrophic.

\section{Evaluate the results and analyse the applicability of the four methodologies}

The results of the single-factor evaluation method differ greatly from the other three methods, with only ZS13, ZS14 and ZS20 having water quality of Type III. The results of the Nemerow index method and the fuzzy mathematical method are similar, with $90 \%$ coincidence in the sections with poor water quality and $\mathrm{TN}$ as the main polluting factor. The results of the Nemerow index method show that $11 \%$ of the sections are of Type II and $77.8 \%$ of the sections are of Type III class. The results of the fuzzy mathematical method evaluation showed that $72 \%$ of the sections were class III.In the overall analysis of the Zijiang River, there is no obvious pattern in the water quality evaluation results. This phenomenon may be related to the increased flow and the uneven distribution of aquatic plants in the Zijiang River in summer. There are seasonal changes in the biological community, and the ability of aquatic plants to remove pollutants is different in different seasons. There are seasonal changes in the biological community in the water, the ability of aquatic plants to purify pollutants is different in different seasons, the runoff increases significantly in July, and there is uncertainty in the water quality due to the complex composition of river water sources during the high water period[13].Through investigations, it was found that Zijiang aquatic plants are widely distributed, with 22 species. Studies have shown that aquatic plants have the highest removal efficiency of total nitrogen and ammonia nitrogen in summer [14]. Wang Xiaoyan and others found that the total nitrogen content in the Taihu Lake Basin is the lowest in summer and autumn[15] .

The single-factor evaluation method judges the water quality grade based on the comparison between the detection index and the water quality standard. Its advantage is that the evaluation is simple and fast, and it can directly reflect the pollution factor exceeding the standard. The disadvantage is that it cannot fully reflect the overall water quality of the river section. The advantage of the improved Nemerow index method is that the weights of $\mathrm{TN}, \mathrm{TP}, \mathrm{NH} 3-\mathrm{N}$, and $\mathrm{COD}_{\mathrm{Mn}}$ in the water quality evaluation are considered, and the worst index is used to judge the water quality of the section, avoiding ignoring some harms due to small measured concentrations. The impact of pollution factors with large coefficients on water quality evaluation results is suitable for judging toxic and harmful substances in rivers, and can more comprehensively evaluate river water quality. Its disadvantage is that there is a certain subjectivity in the classification of water quality.The advantage of fuzzy mathematics comprehensive evaluation method is that it takes into account the ambiguity of water quality classification boundaries and the weight of pollution factors, and can objectively and comprehensively evaluate the water quality status. By calculating the weight of evaluation factors and the degree of membership, the impact of each evaluation factor on water quality can be known. The advantage of the comprehensive nutrient status index method is that the eutrophication status of the water body can be directly judged through calculation. If the water body is eutrophication, combined with the improved Nemerow index method, the pollution factors that lead to the eutrophication of the water body can be determined, and the two are correlated, Analysis can verify the evaluation results. The disadvantage is that only the nutritional status can be determined in a single application, and the pollution factor cannot be judged.

\section{Conclusion}

(1) The water quality of 36 sections in Zijiang was evaluated. Zijiang River has serious nitrogen pollution in summer and TN is the main pollution factor.

(2) The single-factor evaluation method is simple to calculate and is suitable for quickly identifying excessive pollutants, but cannot comprehensively reflect the water quality of the water body. The Nemerow index method takes into account the weight of each evaluation factor in the river water quality, and is suitable for making a comprehensive assessment of the river water quality Evaluation, but it is subjective in the classification of water quality. The fuzzy comprehensive evaluation method calculates the weight and membership degree of each evaluation factor, which is suitable for reflecting the impact of different evaluation factors on water quality, but the calculation is complicated. The comprehensive nutritional status index method is applicable.To determine whether the water body has eutrophication, it is impossible to determine the water quality category, and it can be combined with other methods to determine the pollution factors that lead to the eutrophication of the water body.

\section{References:}

1. Y.L.Zhang,Y.Zhou, et al.Application Comparison of Different Water Quality Evaluation Methods $i$ $n$ Danjiangkou Basin Water Quality Evaluation, 
Environ.Monit.China,31(2015)

2. Kimura, Masaomi,Noda.Seasonal characteristics of surface water quality in the wastewater catc hment system of an urbanizing basin.Paddy \& Water Environment,(2018)

3. M.A.Soares Cruz,A.D.A.Goncalves,et al.Spatial a nd seasonal variability of the water quality cha racteristics of a river in Northeast Brazil,Enviro nmental Earth ences, 78(2019)

4. Peters M,Guo Q,Strauss H,et al.Seasonal effects on contamination characteristics of tap water fr om rural Beijing: A multiple isotope approach.J ournal of Hydrology,(2020)

5. T.J. Hou,Y.Gao,Analysis on the Characteristics a nd Causes of Water and Sediment Variation in Zishui, Hunan, Water Resources and Hydropower Express,39(2018)

6. F.Luo,G.R.Wu,C.Wang,Application of Nemerow $p$ ollution index method and Single factor evaluati on method in water quality evaluation, Environm ent and Sustainable Development,(2016)

7. Z.Wang,S.J.Zhu,Y.Liu, Comparison of Water Qua lity Assessment Methods in the Lower Luan Riv er Region, Water-saving irrigation,10(2019)

8. L.J.Wang,C.H.Li,Groundwater quality evaluation of Shenyang section of Liaohe River based on $i$ mproved fuzzy mathematics, Ground Water, (2019 )

9. R.X.Huang,The evaluation of groundwater enviro nmental quality in bozhou based on fuzzy math ematics comprehensive evaluation, Ground Water, (2018)

10. Y.M.Ning,F.N.Yin,Water Quality Evaluation Base $d$ on Improved Nemerow Pollution Index Metho $d$ and Grey Clustering Method,J.Cent. China No rm. Univ.Nat.Sci,54(2020)

11. M.C.Wang, X.Q.Liu,J.H.Zhang,Evaluation method and classification standard of lake eutrophicati on,Environ. Monit.China,5(2002)

12. G.Q.Bao, L.Yin ,J.L. Yu ,C. Liu,X.C.Qiu,Eutrop hication evaluation of Heihe based on compreh ensive nutritional status index and BP neural $n$ etwork,Bulletin of Soil and Water Conservation, 38(2018)

13. K.E.Boyer,P.Fong,R.R.Vance,R.F.Ambrose, Wetland s, 21(2001)

14. C.Wang, Y.Q.Chen,L.J.Cai, Z.Zuo,B.X.Cheng, $P u$ rification effects of large-scale ecological purific ation projects in different seasons on nitrogen $i$ $n$ raw water,Chin. J. Environ.Eng,9(2015)

15. X.Y.Wang,S.Zhong,Study on Changes of Ammoni a Nitrogen and Total Nitrogen Content in Taihu Lake Basin in Different Seasons,Anhui Agric.S ci,(2014) 